\title{
Finite element simulation of impact response of wire mesh screens
}

\author{
Caizheng Wang ${ }^{\mathrm{a}}$, Krishna Shankar, and Alan Fien \\ School of Engineering and Information Technology, UNSW Canberra, ACT 2600, Australia
}

\begin{abstract}
In this paper, the response of wire mesh screens to low velocity impact with blunt objects is investigated using finite element (FE) simulation. The woven wire mesh is modelled with homogeneous shell elements with equivalent smeared mechanical properties. The mechanical behaviour of the woven wire mesh was determined experimentally with tensile tests on steel wire mesh coupons to generate the data for the smeared shell material used in the FE. The effects of impacts with a low mass $(4 \mathrm{~kg})$ and a large mass $(40 \mathrm{~kg})$ providing the same impact energy are studied. The joint between the wire mesh screen and the aluminium frame surrounding it is modelled using contact elements with friction between the corresponding elements. Damage to the screen of different types compromising its structural integrity, such as mesh separation and pulling out from the surrounding frame is modelled. The FE simulation is validated with results of impact tests conducted on woven steel wire screen meshes.
\end{abstract}

\section{Introduction}

Security screen doors and window grilles (Fig. 1) are increasingly employed in a number of domestic, commercial and industrial buildings in Australia, for allowing free circulation of air in hot weather, keeping insects from entering the premises, and more importantly providing substantial resistance to forced entry [1]. Security screens are also increasingly being employed to protect against damage from natural sources such as cyclone debris. Hence, the determination of impact resistance of wire mesh security screens is essential and necessary. Traditionally, the design of these security screens has been done using trial and error methods and experimental impact testing. Extensive experimental testing is impractical and expensive and can be avoided by using numerical models that predict the response of the security screen to impact.

However, there is hardly any literature directly related to the modelling of wire mesh security screens. There have been some studies conducted on modelling of steel meshes for rock fall protection [2,3] and simulation of impact and ballistic resistance of woven fabrics [4-8]. There are several approached employed to represent woven structures. Single scale modelling techniques include representing the entire fabric as homogenized membranes or plates [4,5], and full detailed modelling with 3D solid finite elements [6]. There are also some meaningful explorations of multi-scale modelling methods, such as G. Nilakantan $[7,8]$ who used a hybrid element analysis method (with both solid and shell elements) to model impact on textile fabrics. Modelling individual wires of a woven wire mesh screen can be very complex and will considerably increase the simulation time (there are over 300 wires in a typical screen running in each direction and criss-crossing over each other); hence, it was considered

\footnotetext{
${ }^{\text {a }}$ Corresponding author: caizheng. wang@student . adfa.edu . au
}

expedient to investigate the approach using homogeneous sheet structure with equivalent properties to simulate the discrete mesh first, as employed by some previous researchers $[4,5,8]$.

In this paper, explicit FE software, LS-Dyna is used to model security screens subjected to impact loading. The impact conditions that are simulated correspond to the Australian Standards for Security Screens (AS 5039), which require that the security screen withstand five impacts at 100J energy without developing a breach large enough to allow intruder access [9]. FE model of same energy level impact of security screens are developed for impactor mass of $4 \mathrm{~kg}$ and $40 \mathrm{~kg}$ in order to study the influence of velocity on the impact response on the wire mesh security screen. The steel woven wire mesh is modelled as a homogeneous continuous sheet using fully integrated Belytschko-Tsay Shell elements and the equivalent smeared were determined using macroscopic material properties of the wire mesh obtained from tensile testing on a Shimadzu Hydraulic machine. A bilinear material model available in the material library as MAT24 was used for the wire mesh. The aluminium frame is modelled using brick elements and elastic-linear material law. The clamping of the wire mesh to the frame is modelled using Tie break contact elements.

\section{Tensile testing woven wire mesh samples}

\subsection{Tensile test setup and results}

To determine the tensile properties of the woven wire mesh, tensile testing was conducted on coupons using the Shimadzu Hydraulic Tensile Test machine shown in Fig. 2. The load was applied under displacement control at the rate of $1 \mathrm{~mm} / \mathrm{min}$. A laser extensometer was used to measure the strain. Two reflective tabs were put on each sample marking the gauge length over which extension 


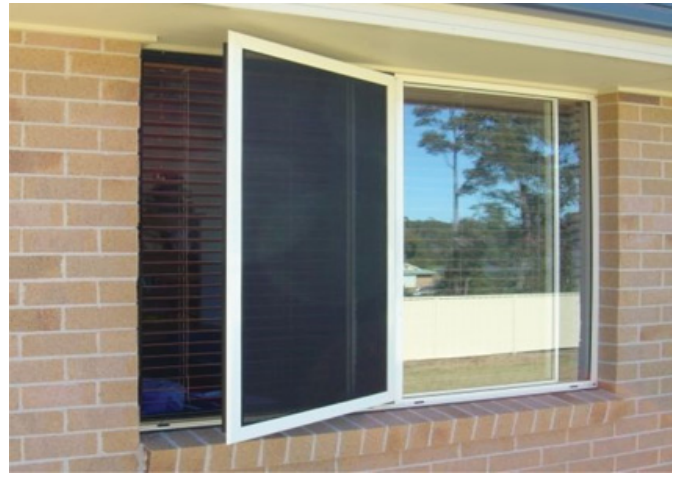

Figure 1. Stainless steel wire mesh security screen.

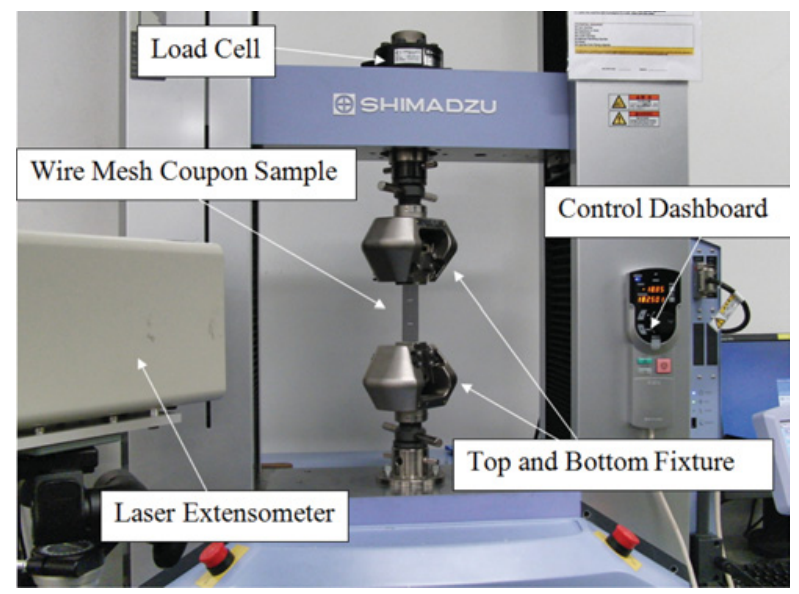

Figure 2. Tensile test setup on Shimadzu test machine.

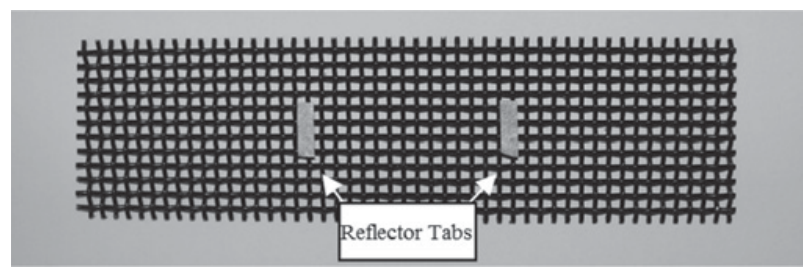

Figure 3. Stainless steel wire mesh tensile test sample.

was measured to determine strain. During the testing, the sample was gripped in pin-mounted fixtures to ensure that only tensile force is applied on the coupon.

The wire mesh coupons employed in this study were cut from an commercially marketed security screen in Australia, made of 304 stainless steel wires (Nominal Young's Modulus $\mathrm{E}=193 \mathrm{GPa}$ ) with a diameter of $0.9 \mathrm{~mm}$ and spacing of $2.5 \mathrm{~mm}$. A total of 5 coupons were tested. Each coupon had a width of $30 \mathrm{~mm}$ containing 12 wires in the loading direction, and a nominal length of 30-40 mm (see Fig. 3).

Figure 4 shows all the samples after testing. It can be seen that the last sample in the picture failed outside the gauge length, so the data from this sample was not included. The plots of load vs engineering strain for the four valid samples are shown in Fig. 5.

\subsection{Equivalent smeared material properties}

Several methods can be employed to model a periodic inhomogeneous structure with a homogeneous continuous

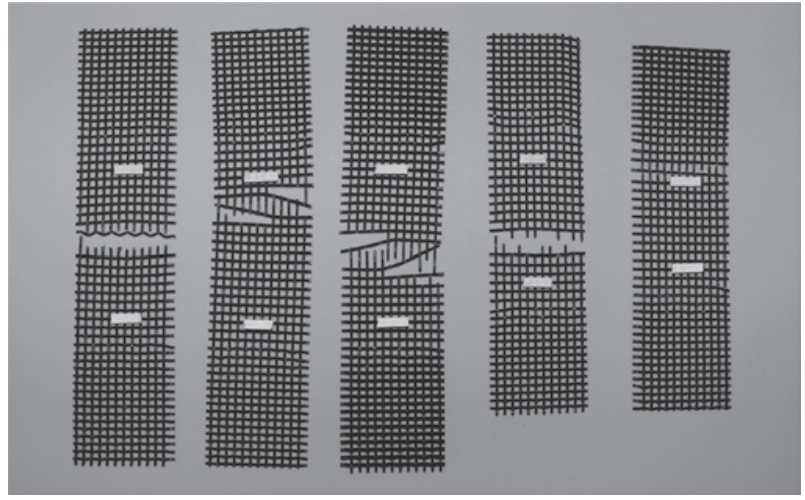

Figure 4. Samples after tensile testing.

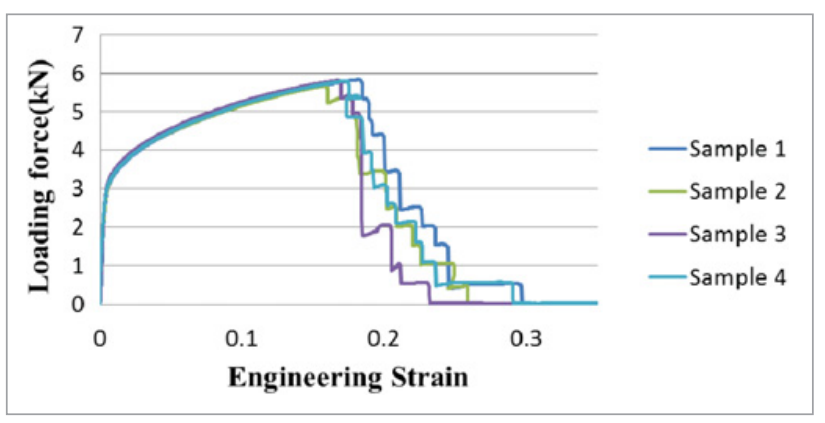

Figure 5. Force vs. engineering strain for tensile test samples.

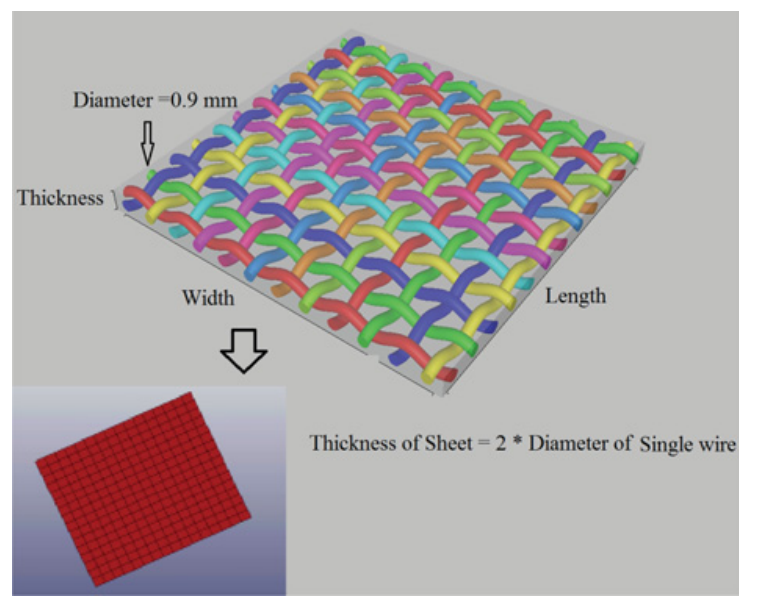

Figure 6. Woven wire mesh and equivalent homogeneous sheet.

structure. C.T. Lim et al. [5] used a mathematical manipulation of the three-element spring-dashpot model to obtain viscoelastic nature material properties of a woven fabric. B.J.E. van Rens [10] determined a perforated plate's smeared properties by calculating finite element model of a representative volume unit (RVU) of the plate. A. Shahkarami and R. Vaziri [6] created a 3D finite element mesh of the unit cell from a woven fabric using the measured fabric cross-sectional micro-images to investigate the smeared material properties.

In this study, the RVU approach of B.J.E. van Rens [10] is adopted. In this approach, by equating the volume of the representative homogeneous sheet (see Fig. 6) to the enclosed rectangular volume of the perforated mesh, the 


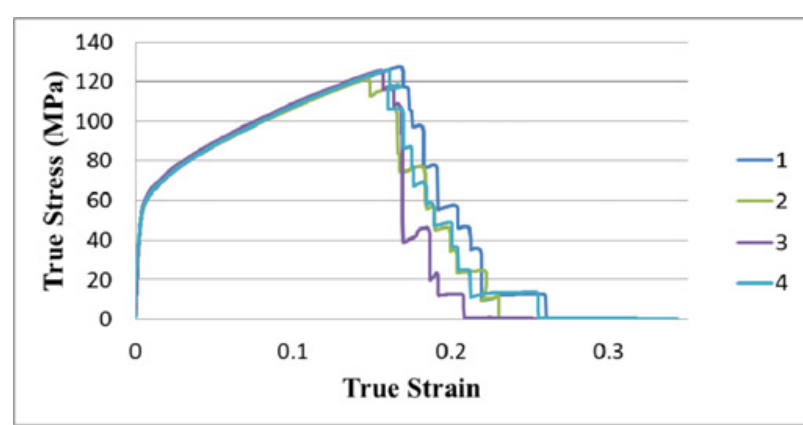

Figure 7. Stress-strain curve of equivalent homogeneous sheet.

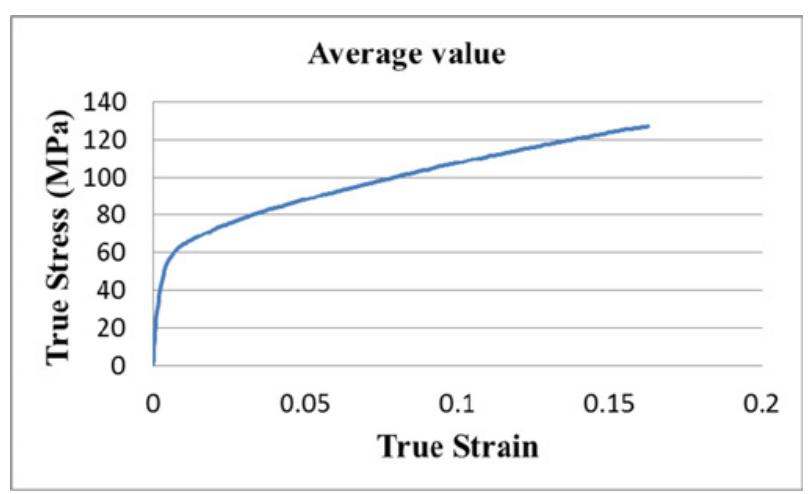

Figure 8. Average equivalent true stress-strain curve.

thickness of the homogenous sheet is obtained as twice the diameter of the wire mesh [8]. The modulus of the sheet material is then determined so as to provide the same effective in-plane stiffness, i.e., gradient of the load strain curve as that measured from coupon tests. Since the response of the wire mesh under tensile loading is non-linear, the equivalent modulus of the representative sheet has to be determined in this manner at all points along the curve, to obtain the stress strain curve of the representative sheet. It is to be noted that in the RVU approach, since the equivalent sheet has a thickness of twice the diameter of the wires; hence although its inplane stiffness would be the same as the over-all in-plane stiffness of the wire mesh, the bending stiffness would be much higher. Figure 7 shows the true stress vs true strain curve of the representative homogenous sheet determined in this manner for the four individual coupons tested. As can be seen the four curves lie very close to each other, except in the post failure region, and the averaged stress strain data (see Fig. 8) is employed for generating the input data for bilinear material model in the FE simulation. In the initial linear region, where the stiffness is constant, the modulus of the equivalent sheet is obtained as $27.28 \mathrm{GPa}$.

\section{Numerical models of wire mesh screens}

The most common failure mode observed in impact testing of wire mesh screens is the pull out of the sheet from the frame. This occurs due to the tensile forces on the individual wires exceeding the friction provided by clamping in the frame, and is accompanied by the wires
Table 1. Equivalent smeared material properties of the representative sheet.

\begin{tabular}{|l|l|l|l|l|l|}
\hline $\begin{array}{l}\text { Young's } \\
\text { Modulus } \\
(\mathrm{GPa})\end{array}$ & $\begin{array}{l}\text { Poisson's } \\
\text { ratio }\end{array}$ & $\begin{array}{l}\text { Yield } \\
\text { Stress } \\
(\mathrm{MPa})\end{array}$ & $\begin{array}{l}\text { Yield } \\
\text { Strain }\end{array}$ & $\begin{array}{l}\text { Tangent } \\
\text { Modulus } \\
(\mathrm{GPa})\end{array}$ & $\begin{array}{l}\text { Failure } \\
\text { Strain }\end{array}$ \\
\hline 27.28 & 0.3 & 36 & $0.20 \%$ & 0.57 & $16 \%$ \\
\hline
\end{tabular}

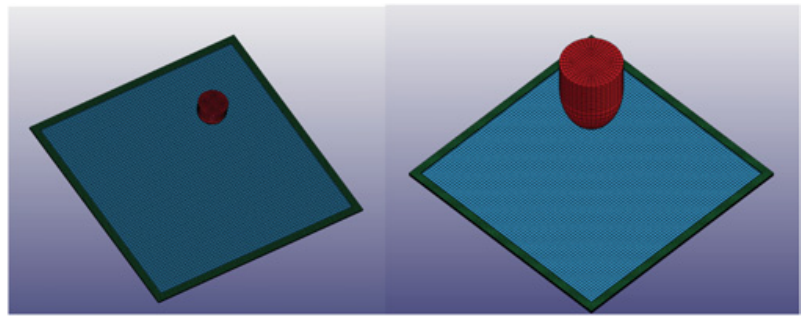

(a)

(b)

Figure 9. Finite Element (FE) models (a) $4 \mathrm{~kg}$ and (b) $40 \mathrm{~kg}$ impactors.

Table 2. Element and Material types.

\begin{tabular}{|l|l|l|l|}
\hline Components & Element type & No. of elements & Material type \\
\hline Impactor & Solid 164 & 5000 & Rigid \\
\hline Screen & Shell 163 & 6400 & MAT24 \\
\hline Frame & Solid 164 & 12400 & Elastic \\
\hline
\end{tabular}

behind screws getting cut as the wire mesh pulls out. The focus of this study was to simulate this mode of failure.

In the LS-Dyna simulation, the homogeneous sheet was modelled with Shell 163 elements with equivalent bi-linear properties listed in Table 1 . The frame surrounding the mesh (see Fig. 9) was modelled using Solid 164 elements with standard aluminium alloy elastic properties (Young's Modulus $73 \mathrm{GPa}$ and Poissson's ratio 0.33 ). The impactor was modelled as rigid with Solid 164 elements. The element type and material models are listed in Table 2.

To investigate the influence of velocity two impactor masses, $4 \mathrm{~kg}$ and $40 \mathrm{~kg}$ were employed with the same input impact energy (Figs. 9(a) and 9(b)).

The 'AUTOMATIC_SURFACE_TO_SURFACE' contact was used to define the contact between the impactor and screen, while the 'CONTACT' type between frames and, shell screen was 'TIEBREAK_SURFACE_TO_SURFA $\mathrm{CE}$, which is typically used to represent bolted or spot- welded connections. Fully fixed (zero displacements and rotations) boundary conditions were applied on the underside surface of the bottom frame and at the outer edges of the top frame.

The screen is $800 \mathrm{~mm} \times 800 \mathrm{~mm}$ in geometry, while the frames are $25 \mathrm{~mm}$ in width and $5 \mathrm{~mm}$ in thickness. The location of impact loading point is also the same, $250 \mathrm{~mm}$ away from frame two adjacent frame edges. The hemispherical impactors of $4 \mathrm{~kg}$ and $40 \mathrm{~kg}$ mass had radii of $50 \mathrm{~mm}$ and $100 \mathrm{~mm}$, respectively.

\section{Simulation results}

\subsection{Effect of impact velocity}

A comparison of the simulations of a single impact of $100 \mathrm{~J}$ using the two impactors masses of $4 \mathrm{~kg}$ (input 
Table 3. Equivalent material properties of the smeared sheet.

\begin{tabular}{|l|l|l|l|}
\hline & $\begin{array}{l}\text { Maximum } \\
\text { Von Mises } \\
\text { Stress in } \\
\text { screen }\end{array}$ & $\begin{array}{l}\text { Maximum } \\
\text { Von Mises } \\
\text { Stress in } \\
\text { frame }\end{array}$ & $\begin{array}{l}\text { Maximum } \\
\text { Screen } \\
\text { Deflection }\end{array}$ \\
\hline $40 \mathrm{~kg}$ impactor & $84.20 \mathrm{MPa}$ & $239.3 \mathrm{MPa}$ & $57.25 \mathrm{~mm}$ \\
\hline $4 \mathrm{~kg}$ impactor & $103.29 \mathrm{MPa}$ & $231.9 \mathrm{MPa}$ & $54.11 \mathrm{~mm}$ \\
\hline
\end{tabular}

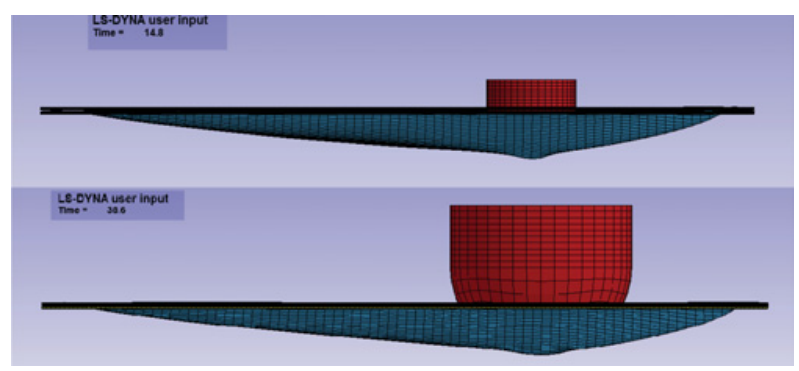

Figure 10. Deformed shape of screen impacted with (a) $4 \mathrm{~kg}$ and (b) $40 \mathrm{~kg}$ mass.

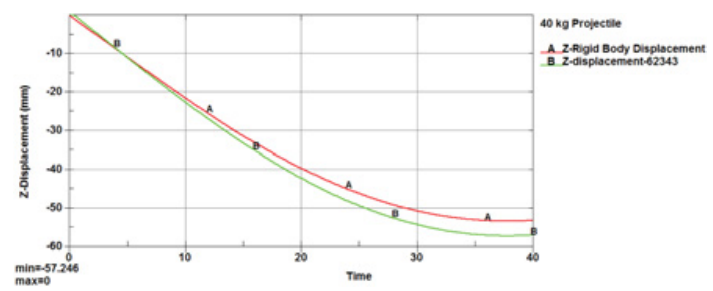

Figure 11. Z-displacements of $4 \mathrm{~kg}$ impactor and screen at contact point.

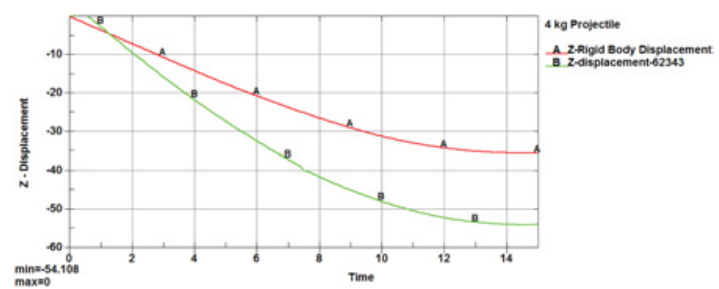

Figure 12. Z-displacements of $40 \mathrm{~kg}$ impactor and screen at contact point.

velocity of $7.07 \mathrm{~m} / \mathrm{s}$ ) and $40 \mathrm{~kg}$ (input velocity of $2.24 \mathrm{~m} / \mathrm{s}$ ) was first performed. Figure 10 shows the deformed shapes of the screens impacted with the $4 \mathrm{~kg}$ and the $40 \mathrm{~kg}$ masses at the instant of maximum contact force. Figures 11 and 12 respectively show the displacement time histories of the impactor and the contact point of the screen, with the $4 \mathrm{~kg}$ mass and the $40 \mathrm{~kg}$ mass. It is evident from these figures that the screen deflects more when impacted with the $40 \mathrm{~kg}$ mass than with the $4 \mathrm{~kg}$ mass (maximum deflection of $57.25 \mathrm{~mm}$ compared to $54.11 \mathrm{~mm}$ of the latter), even the kinetic energy of both are impactors before contact are the same. The maximum stress experienced by the screen are also higher when impacted with the lower mass compared to those for the higher mass (see Table 3), which may be attributed to the higher velocity of the impactor with the lower mass providing less time for the stresses and energy to be transmitted to the surrounding frame. Figures 13 and 14

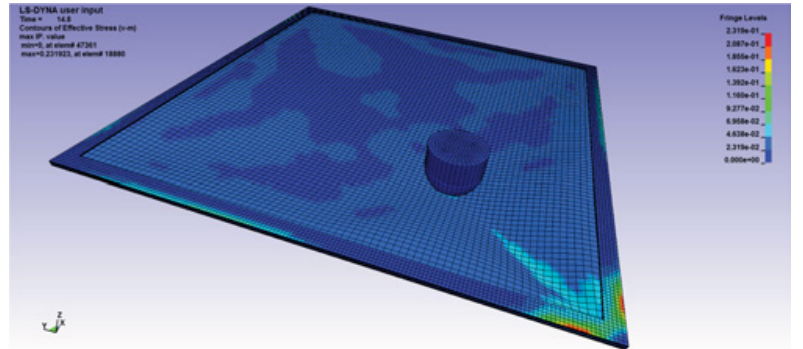

Figure 13. Contour map of Von Mises Stress of screen on impact with $4 \mathrm{~kg}$ mass at $100 \mathrm{~J}$ at $14.8 \mathrm{~s}$.

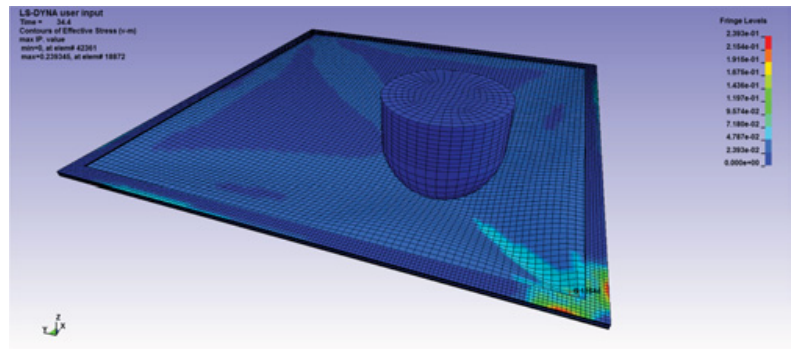

Figure 14. Contour map of Von Mises Stress of screen on impact with $40 \mathrm{~kg}$ mass at $100 \mathrm{~J}$ at $34.4 \mathrm{~s}$.

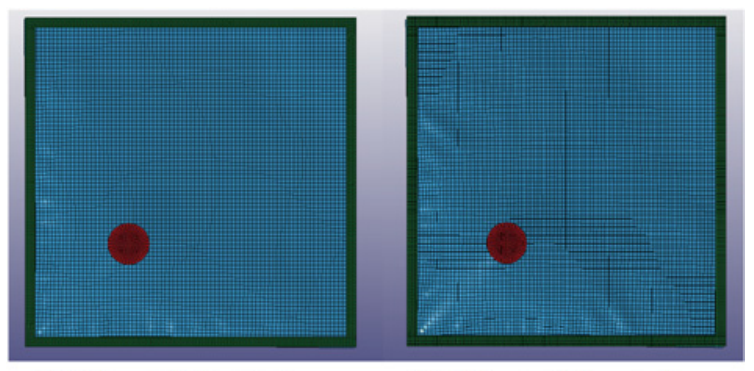

(a) $100 \mathrm{~J}$ Impact with $4 \mathrm{~kg}$ projectile

(b) 200J Impact with $4 \mathrm{~kg}$ projectile

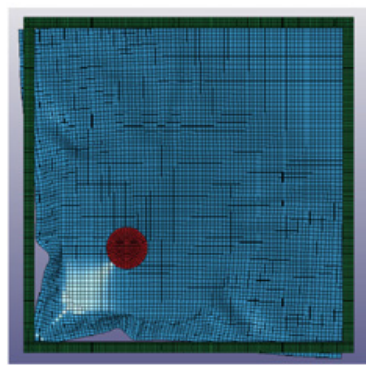

(c) $500 \mathrm{~J}$ Impact with $4 \mathrm{~kg}$ projectile

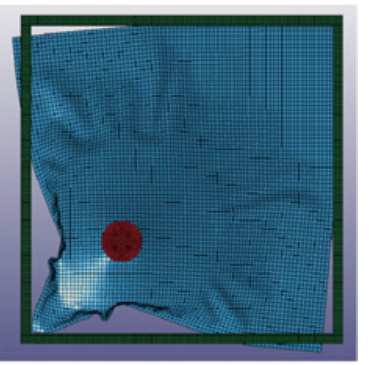

(d) $800 \mathrm{~J}$ Impact with $4 \mathrm{~kg}$ projectile

Figure 15. Response of wire mesh security screen on impact with $4 \mathrm{~kg}$ mass at different energy levels.

show the contour maps of Von Mises stress distributions in the screen and the frame, 14.8 seconds after impact with $4 \mathrm{~kg}$ mass and 34.4 seconds after impact with $40 \mathrm{~kg}$ mass, respectively. The development of high stresses in the scree and the frame at the corner near the impact point are evident in both cases.

\subsection{Impacts at increasing energy levels}

Simulations were performed at four impact energy levels, viz., $100 \mathrm{~J}, 200 \mathrm{~J}, 500 \mathrm{~J}$ and $800 \mathrm{~J}$, with the $4 \mathrm{~kg}$ mass and the $40 \mathrm{~kg}$ mass to investigate the development of 


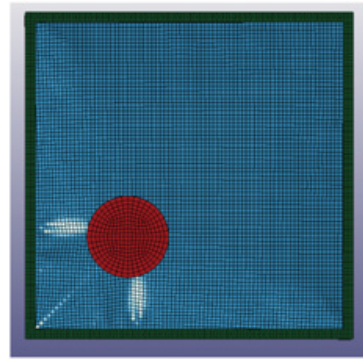

(a) $100 \mathrm{~J}$ Impact with $40 \mathrm{~kg}$ projectile

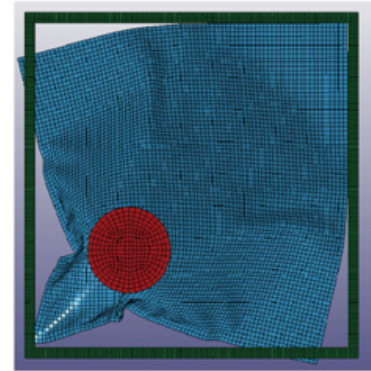

(c) $500 \mathrm{~J}$ Impact with $40 \mathrm{~kg}$ projectile

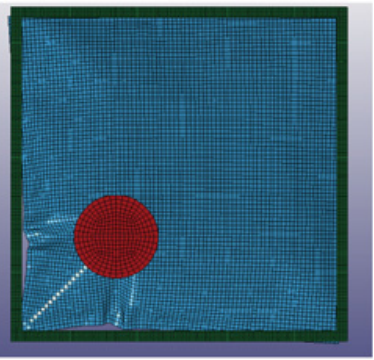

(b) 200J Impact with $40 \mathrm{~kg}$ projectile

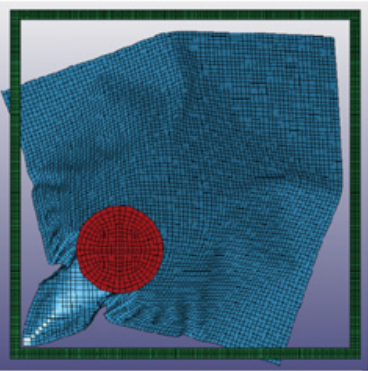

(d) $800 \mathrm{~J}$ Impact with $40 \mathrm{~kg}$ projectile
Figure 16. Response of wire mesh security screen on impact with $40 \mathrm{~kg}$ mass at different energy levels.

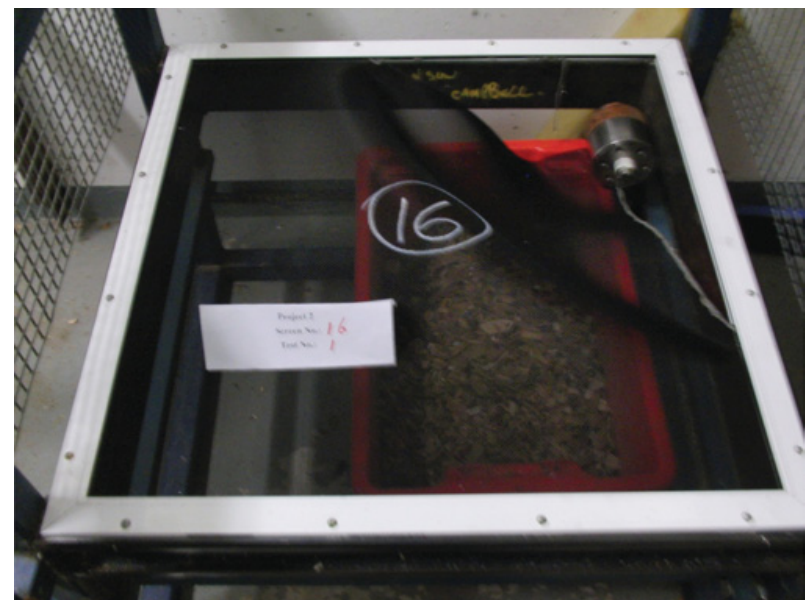

Figure 17. Woven wire mesh security screen after a singular impact of $500 \mathrm{~J}$.

damage. The deformed shapes of the screen impacted with the $4 \mathrm{~kg}$ mass at these four energy levels are shown in Figs. 15(a) to 15(d) and those for impacts with the $40 \mathrm{~kg}$ mass are shown in Figs. 16(a) to 16(d). It can be seen that while the screens are undamaged when impacted with both masses at $100 \mathrm{~J}$, the wire mesh stats pulling out from the corner on impact with $200 \mathrm{~J}$ with the $40 \mathrm{~kg}$ mass, but is still fairly undamaged when impacted at $200 \mathrm{~J}$ with the $4 \mathrm{~kg}$ mass. At $500 \mathrm{~J}$ both screens exhibit considerable damage in the form of pull out of the mesh from the frame at the impact corner, developing into pull out at other corners and along the sides of the frame when the energy is increased to $800 \mathrm{~J}$.

For comparison, Fig. 17 shows the photograph of a wire mesh screen impacted with $500 \mathrm{~J}$ of energy with a $4 \mathrm{~kg}$ mass during impact testing. As can be seen, the real screen also failed by mesh pulling out from the frame edges at the impact corner. The breaches between the frame and the mesh in the experimental screen are $510 \mathrm{~mm}$ and $420 \mathrm{~mm}$ long, while those obtained in the simulation for impact at $500 \mathrm{~J}$ with the $4 \mathrm{~kg}$ mass are $511 \mathrm{~mm}$ and $494 \mathrm{~mm}$, indicating good agreement between the simulation and the testing.

\section{Conclusion}

This paper looked at the impact behaviour of woven wire mesh security screen subjected to low velocity impact loading using a smeared homogeneous model for the perforated screen. It is seen the responses of screen are different for impacts at the same energy with a low mass and relatively high mass with the same impact energy. With a $4 \mathrm{~kg}$ mass the maximum deflection is lower but the stresses are higher in the mesh, while the higher mass of $40 \mathrm{~kg}$ produces higher screen deflection and higher stresses in the frame. The latter may account for the fact damage in the form of separation between the mesh and the frame appears to occur at lower impact energies when the $40 \mathrm{~kg}$ mass is employed compared to damage initiation when impacted with the lower mass.

The damage mode and failure observed in experimental testing was very similar to those predicted by the simulation, providing validation for the finite element model developed. To predict other modes of failure, the model has to be developed further to include details of the geometry of the frame and individual woven wires, which will be undertaken in future work.

\section{References}

[1] D. Smith, S. Grove, Window security screen and latch assembly, U.S. Patent, Appl. No.: 13/410,379 (2012)

[2] A. Volkwein, Numerical simulation of flexible rockfall protection systems, Computing in Civil Engineering (2005)

[3] E.C. Morton, A.G. Thompson \& E. Villaescusa, Testing and analysis of steel wire mesh for mining applications of rock surface support, 11th congress of the International Society for Rock Mechanics, Vol. 2, 1061-1064 (2007)

[4] A. Shahkarami, R. Vaziri, A continuum shell finite element model for impact simulation of woven fabrics. International Journal of Impact Engineering 2007, 34:104e19

[5] C.T. Lim, V.P.W. Shim, Y.H. Ng, Finite-element modeling of the ballistic impact of fabric armor, International Journal of Impact Engineering 2003, 28: $13 \mathrm{e} 31$

[6] E. Glatt, S. Rief, A. Wiegmann, Structure and pressure drop of real and virtual metal wire meshes, Berichte des Fraunhofer ITWM, ISSN 1434-9973, Nr. 157 (2009)

[7] G. Nilakantan, M. Keefe, T. A. Bogetti, J. W. Gillespie, Multiscale modeling of the impact of textile fabrics based on hybrid element analysis, 
International Journal of Impact Engineering, Vol. 37, 1056-1071(2010)

[8] G. Nilakantan, M. Keefe, T. A. Bogetti, R. Adkinson, J. W. Gillespie, On the finite element analysis of woven fabric impact using multiscale modeling techniques, International Journal of Solids and Structures, Vol. 47, Issue 17, 2300-2315 (2010)
[9] S. Australia, AS 5039-2008 Security screen doors and security window grilles, in, Standards Australia, Sydney, NSW (2008)

[10] B. J. E. van Rens, W. A. M. Brekelmans, F. P. T. Baaijens, Homogenization of the elasto plastic behavior of perforated plates, Computers and Structures, 537-545, 69 (1998) 